\title{
EVIDENCIAÇÃO E DESEMPENHO EM ORGANIZAÇÕES DESPORTIVAS: UM ESTUDO EMPÍRICO SOBRE CLUBES DE FUTEBOL
}

\section{DISCLOSURE AND PERFORMANCE ON SPORTS ORGANIZATION: AN EMPIRIC STUDY ABOUT FOOTBALL CLUBS}

\author{
JOSÉ ANTONIO FELGUEIRAS DA SILVA \\ Mestre em Ciências Contábeis pela Universidade do \\ Estado do Rio de Janeiro \\ Contador do Banco Nacional de Desenvolvimento \\ Econômico e Social \\ Rio de Janeiro/RJ, Brasil \\ E-mail: joseantonio@bridge.com.br
}

\author{
FREDERICO ANTONIO AZEVEDO DE CARVALHO \\ Doutor em Sciences Économiques pela \\ Universite Catholique de Louvain, Bélgica \\ Professor Associado da Faculdade de Administração e Finanças \\ da Universidade do Estado do Rio de Janeiro \\ Rio de Janeiro/RJ, Brasil \\ E-mail: fdecarv@gmail.com
}

\section{Resumo}

No "país do futebol" muitos clubes de tradição não conseguem honrar seus compromissos financeiros. Parece premente a revisão do atual modelo de negócio do futebol brasileiro. Rever modelos de negócio requer, ao mesmo tempo, rever mecanismos de governança. 0 presente trabalho pretende ilustrar empiricamente que a evidenciação pode fazer parte desses mecanismos de governança sem que a organização desportiva perca eficiência ou eficácia. Para atingir este objetivo foram analisadas as demonstrações contábeis dos clubes de futebol da $1^{\text {a }}$ divisão do campeonato brasileiro de 2004, mensurando-se o nível de evidenciação e relacionando-o ao desempenho desses clubes. A hipótese de ausência de correlação foi testada não-parametricamente, por meio do coeficiente de correlação ordinal. Os resultados indicaram que os clubes que evidenciam suas demonstrações contábeis em maior grau são essencialmente os mesmos que apresentam melhores resultados no campo e em termos financeiros. Pode-se, então, concluir que a evidenciação é compatível com a modernização e com a abertura da governança em direção aos públicos-alvo do futebol.

Palavras-chave: evidenciação; desempenho; clubes de futebol; análise multivariada.

\begin{abstract}
In Brazil several football clubs of centennial tradition cannot manage to accomplish their financial duties. It seems that an overall reform in Brazilian football's business model is urgently needed. When business models are reformed, governance formats must be altered correspondingly. This paper intends to illustrate that corporate transparency may be required from those new business models without clubs being deprived from neither efficiency nor effectiveness. With the help of financial statements data relating to a convenience sample of clubs, disclosure indicators are first defined and measured, and then correlated to some performance indicators. The null hypothesis of no correlation between disclosure and performance was tested via rank correlation. Findings indicate that the more disclosure a club chooses to provide, the better their performance, both in the national championship and in financial terms. It may be suggested that corporate transparency is compatible with modernization and with open governance models for football clubs.
\end{abstract}

Key words: disclosure, performance, football clubs, multivariate analysis. 


\section{INTRODUÇÃO}

No Brasil, clubes de futebol sempre foram considerados entidades sem fins lucrativos. Antes da Lei Pelé, nunca prestaram contas à sociedade. A partir da vigência da Lei Pelé, os clubes enfrentam um novo desafio - passar de clubes sociais para clubesempresas. Os Estados, as Federações Esportivas nacionais e estaduais, a Confederação Brasileira de Futebol - CBF, o Clube dos Treze e tantas outras entidades devem adequar-se ao novo ambiente.

Segundo Neto (1998, p. 72), "é ilusão pensar que o aumento do fluxo de dinheiro nos negócios caracteriza a passagem do amadorismo para o profissionalismo". Se, por um lado o profissionalismo avança nas relações de trabalho com os empregados do clube (dirigentes, atletas, técnicos, auxiliares) e na compra e venda de jogadores, por outro lado, não ocorre o mesmo na administração dos negócios dos clubes, e muito menos em sua transparência organizacional.

Uma forma de avaliar a transparência de organizações, tenham ou não fins lucrativos, é analisar seus demonstrativos contábeis. A partir da publicação da Lei $\mathrm{n}$. $^{\circ}$ 10.672, de 15 de maio de 2003, os clubes de futebol ficaram obrigados a elaborar e a publicar demonstrações contábeis na forma definida na Lei 6404/76 (Lei das Sociedades Anônimas), após auditadas por auditores independentes. Como ocorre com outros tipos de organização, as demonstrações contábeis dos clubes, também sujeitas aos Princípios Fundamentais da Contabilidade, constituem importante veículo de comunicação do clube com seu ambiente de negócios.

No entanto, apesar de geralmente reconhecidas, desde muito tempo as vantagens da eventual obrigação legal de divulgar amplamente suas informações são vistas com reservas no dia a dia de muitas organizações. Por exemplo, para Gray, Radebaugh e Roberts (1990) os executivos financeiros tendem a considerar que a evidenciação representa um "custo líquido" e que o fator de custo mais importante se refere à possível desvantagem frente aos concorrentes.

No caso das informações contábeis, a literatura sobre evidenciação tem considerado tais informações como um mecanismo simples e ingênuo, indicando apenas boas ou más notícias (SKOGSVIK, 1998). Em contraste, alguns autores reconhecem na evidenciação de informações contábeis a vantagem de fornecer informações que podem ser fundamentais para valuation analysis (IDEM, p. 361). Para Zimbwa (2005), mais evidenciação pode ser a resposta à diminuição periódica da confiança na Contabilidade tradicional (p. 2).

Neste trabalho postula-se que uma forma consagrada para avaliar o desempenho de organizações, tenham ou não fins lucrativos, é a análise dos seus demonstrativos contábeis. Assim, ao analisar os balanços dos clubes será possível avaliar a situação econômica e financeira em que se encontram. Em outras palavras, a elaboração e a análise das demonstrações contábeis deva propiciar melhores decisões não somente aos próprios clubes, mas também aos diversos agentes econômicos e sociais que interagem com os clubes.. O esforço despendido pelos clubes para cumprir as exigências estabelecidas na Lei Pelé deve trazer, entre outros benefícios, a melhoria da imagem da instituição e a valorização de sua marca e de seus atletas. No entanto, adverte Leoncini (2001), os clubes de futebol se veem diante de uma situação inusitada: por um lado, a pressão social, traduzida na chamada Lei Pelé; por outro lado, a situação financeira da maioria, endividados e sem caixa, assume caráter emblemático de ineficácia administrativa e desvalorização de seu produto ou marca.

Em termos acadêmicos, até pouco tempo era reduzido o volume de pesquisa dedicada às demonstrações contábeis obrigatórias publicadas pelos clubes de futebol no 
Brasil, bem como de sua utilização ou da percepção sobre sua utilidade por parte dos diversos públicos-alvo. Em anos recentes apareceram diversas contribuições, tais Amador (2004), Rezende, Facure e Dalmácio (2009), Silva (2007), e Silva, Teixeira e Niyama (2009).

Neste estudo não se pretende investigar por que deveria haver relação entre evidenciação e desempenho. A literatura especializada, que é brevemente revista adiante, já tratou longamente desse tema. A abordagem aqui adotada é essencialmente empírica, de modo que a questão que interessa analisar se refere à existência de evidência empírica que aponte naquela direção, ou seja, a pergunta de pesquisa a responder pode expressa como: existe relação entre transparência e desempenho dos clubes de futebol da $1^{\text {a }}$ divisão do campeonato brasileiro?

Para ampliar o escopo empírico, a idéia de desempenho será captada por meio de diferentes conceitos. Diante desta pergunta, o estudo assume dois objetivos:

(a) propor e aplicar um indicador do grau de evidenciação das demonstrações contábeis de clubes selecionados, utilizando como base não somente as informações diretamente relevantes, complementares e suplementares, mas também o parecer dos auditores independentes; e

(b) investigar se existe relação entre evidenciação e desempenho.

$\mathrm{O}$ texto está organizado em quatro seções, que se seguem a esta introdução. $\mathrm{Na}$ primeira são revistas as fontes bibliográficas que dão apoio ao trabalho, seguidas da metodologia empregada na segunda seção. Os resultados obtidos aparecem na terceira seção, enquanto que as conclusões constituem a quarta e última seção.

\section{ANTECEDENTES}

Nesta seção são brevemente revistas algumas fontes bibliográficas selecionadas, que dão apoio ao estudo. A primeira subseção apresenta um resumo sobre a evolução recente da interface entre gestão e clubes de futebol, historiando-se brevemente o enquadramento legal e institucional das organizações desportivas. A seguir se discute a conceituação de evidenciação, focalizando a evidenciação contábil. Na terceira subseção é revista a literatura que trata da relação entre evidenciação e desempenho organizacional. Finalmente, a quarta subseção discorre sobre mensuração da evidenciação, enfatizando a consideração sobre aspectos da evidenciação voluntária. Como sempre ocorre em revisões de literatura, o objetivo aqui não poderia ser de "apresentar novidades", mas apenas de relatar as bases bibliográficas que fundamentem satisfatoriamente a pesquisa.

\subsection{A NOVA ADMINISTRAÇÃO ESPORTIVA - AS LEIS QUE MUDARAM A GESTÃO DO FUTEBOL}

A primeira lei que tratou de forma mais direta o assunto foi a chamada Lei do Passe (Lei n. ${ }^{\circ}$ 6.354/76). Esta lei garantia aos clubes formadores de atletas a possibilidade de usufruir o direito sobre o futebol deste jogador. Por se tratar de um bem para a instituição, esta poderia se desfazer do mesmo para sanear suas dívidas. Porém, o poder sobre o destino de seus atletas não trouxe necessariamente boa saúde financeira. Naquela época, o esporte não movimentava o mesmo volume de recursos do que atualmente, os torneios não eram transmitidos ao vivo pela televisão, fator que hoje representa a maior parte das receitas dos clubes.

Clubes tais como Corinthians e Flamengo eram muito respeitados pelo que significavam como instituição, porém não poderiam ser considerados exemplos de 
negócios. Esses dois clubes citados são aqueles que possuem as maiores torcidas do país e, teoricamente, os que negociavam os produtos (atletas) de maior demanda.

Outra lei muito importante para o esporte foi à chamada Lei Zico (Lei n. ${ }^{\circ} 8.672 / 93$ ). A principal novidade apresentada por esta lei foi a possibilidade dos clubes serem gerenciados por entidades com fins lucrativos e foi também o embrião da intenção do governo de transformar os clubes em empresas. A lei não foi bem aceita pelos dirigentes visto que o enquadramento neste novo conceito eliminaria uma série de vantagens fiscais que os clubes possuíam.

Em 1998, foi lançada a Lei Geral sobre os Desportos, também chamada de Lei Pelé (Lei n. ${ }^{\circ}$ 9.615/98). Essa regulamentação apresentou novidades que mexeram muito com a estrutura dos clubes. Uma delas foi a extinção do passe, impedindo que os clubes negociem os direitos sobre seus ativos denominados atletas, o que reduziu sensivelmente a receita dos clubes. Na verdade, o passe não foi totalmente extinto naquele momento. Os clubes poderiam firmar contratos com jogadores por eles formados até a idade de 23 anos, momento em que o atleta adquiriria os direitos sobre seu passe, podendo firmar novos compromissos com qualquer outro clube.

Outro ponto bastante polêmico da Lei Pelé foi a obrigatoriedade de os clubes se tornarem empresas. Transformar os clubes em empresas tornou-se um verdadeiro pesadelo para boa parte dos dirigentes brasileiros. Algumas dessas instituições serviam a seus "cartolas" como trampolim eleitoral, fonte inesgotável de corrupção e apropriação indébita. $O$ fato é que a mudança poderia ser até muito benéfica para os clubes, mas seria um obstáculo aos interesses dos seus responsáveis. Vale destacar a advertência de Rezende, Facure e Dalmácio (2009, p. 14) no sentido de que não é suficiente alterar o enquadramento societário e institucional, sendo necessário, também, promover a efetiva implementação das práticas da boa governança.

Em 2003, outras duas regulamentações alterariam em muito a forma de trabalhar das entidades desportivas. A primeira foi o Estatuto do Torcedor (Lei n. ${ }^{\circ} 10.671 / 93$ ) que trouxe alterações sobre os direitos dos torcedores em termos de cliente do futebol como "serviço/produto", equiparando-o ao comprador de outros tipos de bens e serviços, e reconhecendo de fato o torcedor como consumidor (REZENDE, FACURE e DALMÁCIO, 2009, p. 3). A segunda, que recebeu o nome de Lei de Moralização do Futebol (Lei n. ${ }^{\circ}$ 10.672/93), trouxe a obrigatoriedade da aprovação das contas em assembleia geral de associados. Outro ponto a destacar foi a necessidade de publicar, em jornais de grande circulação, as demonstrações contábeis de cada período, devidamente aprovadas por auditores independentes. Por último, um dos pontos marcantes da lei é a responsabilização dos dirigentes em caso de má administração dos clubes.

A Lei 10.672 de 15 de maio de 2003 introduziu no texto da Lei Pelé (Lei 9.615/1998), o artigo 46-A, em que as entidades de prática desportiva, ou seja, os clubes de futebol envolvidos em qualquer competição de atletas profissionais, independentemente da forma jurídica adotada, ficam obrigadas a

"elaborar e publicar, até o último dia útil do mês de abril, suas demonstrações financeiras na forma definida na Lei 6.404/76, após terem sido auditadas por auditores independentes".

Muito a propósito, para Silva, Teixeira e Niyama (2009, p. 3), esta Lei 10672 foi a regulamentação decisiva em termos da transparência administrativa e financeira das organizações desportivas.

Em termos gerais, no Brasil, o conjunto típico de demonstrações financeiras que as sociedades devem elaborar a cada exercício social é estabelecido por Lei. Em 15 de dezembro de 1976 foi aprovada a Lei 6.404, dispondo sobre as sociedades por ações, que 
contempla os aspectos relativos à escrituração contábil, bem como à elaboração e publicação das demonstrações financeiras. Os artigos 176 e 186 daquela Lei enumeram as peças contábeis que devem ser elaboradas pelas sociedades, pelo menos uma vez a cada período de 12 meses, podendo este período coincidir ou não com o ano civil. 0 referido diploma legal estabelece as seguintes demonstrações:

- Balanço Patrimonial;

- Demonstração do Resultado do Exercício (DRE);

* Demonstração das Origens e Aplicações de Recursos (DOAR);

- Demonstração dos Lucros ou Prejuízos Acumulados; e

- Demonstração das Mutações do Patrimônio Líquido.

A Lei, adicionalmente, exige que as demonstrações sejam complementadas por notas explicativas e outros quadros analíticos necessários para esclarecimento da situação patrimonial e do resultado do exercício. Este conjunto de demonstrativos requer razoável conhecimento contábil para sua adequada interpretação. Eles são elaborados obedecendose aos princípios fundamentais de contabilidade e contemplando a legislação tributária e societária complementar.

Cumprindo seu papel como ator na esfera pública, o Conselho Federal de Contabilidade aprovou, em 2004, através da Resolução CFC n. ${ }^{\circ} 1.005$, a NBC T 10.13, que trata dos aspectos contábeis específicos em entidades desportivas profissionais. A importância dessa norma foi disciplinar e padronizar critérios e procedimentos específicos de avaliação, de registros contábeis e de estruturação das demonstrações contábeis das entidades de futebol profissional e demais práticas desportivas. Alguns dos pontos mais importantes desta norma se referem aos gastos com a contratação ou renovação de contrato de atletas, recomendando seu registro no ativo imobilizado e recomendando a amortização dos direitos contratuais de acordo com o prazo do contrato. Cabe destacar também, que, segundo a NBC 10.13, a multa contratual recebida pela liberação do atleta deve ser registrada em conta específica de receita operacional do exercício.

\subsection{CONCEITUAÇÃO DE EVIDENCIAÇÃO}

Usualmente, evidenciação é entendida como divulgação. A palavra evidenciar, de acordo com o dicionário da língua portuguesa de Aurélio Buarque de Holanda, significa "tornar evidente, mostrar com clareza". A palavra divulgar, segundo o mesmo dicionário, significa "tornar público ou notório; publicar; propagar; difundir" (FERREIRA, 2004).

É função da Contabilidade fornecer informações que evidenciem a situação dos clubes de futebol e que satisfaçam a expectativa de usuários e investidores na avaliação do desempenho financeiro e operacional desse tipo de organização. Para ludícibus (2000 p. 121), a evidenciação é um compromisso inalienável da Contabilidade para com seus usuários e para com seus próprios objetivos, realçando que:

\footnotetext{
“As formas de evidenciação podem variar, mas a essência é sempre a mesma: apresentar informação quantitativa e qualitativa de maneira ordenada, deixando o menos possível de fora dos demonstrativos formais, a fim de propiciar uma base adequada de informação para o usuário" (p. 121).
}

De fato, na prática contábil são diversas as formas para evidenciar uma informação. Os elementos usuais de Evidenciação Contábil mais comumente referidos na literatura são: a Forma e Disposição das Demonstrações Contábeis; as Informações entre Parênteses; as 
Notas Explicativas; os Quadros e Demonstrações Suplementares; o Parecer dos Auditores Independentes; o Relatório da Administração; e os Relatórios Periódicos.

O primeiro elemento - Forma e Disposição das Demonstrações Contábeis é seguramente o que proporciona a maior quantidade de evidenciação. Segundo ludícibus (2000), a colocação das demonstrações contábeis em uma forma ordenada melhora sua interpretabilidade e ajuda a melhorar a evidenciação.

A evidenciação das Informações entre Parênteses implica em maiores esclarecimentos sobre um determinado grupo ou critério de avaliação utilizado, ainda dentro do corpo das demonstrações formais.

As Notas Explicativas são, talvez, o mais conhecido elemento de evidenciação. Seu principal objetivo é evidenciar as informações que não são apresentadas na estrutura das demonstrações contábeis.

Os Quadros Suplementares podem ser utilizados, para apresentar maiores detalhes de itens que constam das demonstrações contábeis tradicionais e que não seriam cabíveis no corpo destes. Já as Demonstrações Suplementares, segundo ludícibus (2000), podem ser de utilização mais ambiciosa, servindo para apresentar demonstrações contábeis sob uma outra perspectiva de avaliação, por exemplo, corrigidos pelo índice geral de preços, ou a custo de reposição.

O Parecer dos Auditores Independentes, por si só, na maioria das vezes, não constitui um elemento de evidenciação, caracterizando-se mais como instrumento de enforcement no processo de divulgação e de aprimoramento da informação contábil, e servindo, também, para conferir credibilidade às informações prestadas pela empresa.

O Relatório da Administração é outra forma do processo de evidenciação e constituise em peça de informação fundamental para os usuários externos. Esse elemento de evidenciação, de natureza fundamentalmente descritiva, permite à empresa utilizar uma linguagem menos técnica, atingindo, portanto, maior número de usuários.

Apesar de freqüentemente confundidas entre si, transparência e evidenciação não coincidem. Por exemplo, a Enron evidenciava muito, mas os investidores estavam "no escuro"; na verdade, muita evidenciação pode causar ruído em vez de aumentar a transparência (HANCOCK, 2004). Assim, evidenciação

Para Bushman, Piotroski e Smith (2004, p. 210), transparência (corporate transparency) é a disponibilização ampla de informações específicas sobre uma empresa (publicly listed firm) para aqueles que estão fora da organização. Os autores consideram que a intensidade de evidenciação é um dos elementos que caracterizam aquela dimensão da transparência que denominam corporate reporting (id., p. 211, Fig. 1) e que compreende o fornecimento periódico de informações específicas, obrigatórias por lei ou não.

\subsection{EVIDENCIAÇÃO E DESEMPENHO}

0 interesse na pesquisa sobre a relação entre evidenciação e desempenho certamente não é novo. A extensão do benefício que uma organização pode auferir ao decidir praticar mais evidenciação é controversa e nada fácil de mensurar, além de carecer de comprovação empírica (BOTOSAN, 1997, p. 324). Em termos mais gerais podese atribuir a Williamson (1985) uma abordagem pioneira sobre a relação entre evidenciação e governança corporativa. Normalmente os estudos empíricos, a partir de 1992, investigaram a influência de certos mecanismos de governança (tais como a estrutura de propriedade ou a existência de diretores independentes) sobre a prática de evidenciação (ZIMBWA, 2005, p. 20). 
Nesta subseção o foco é inverso. Procura-se listar duas abordagens que indicam como a evidenciação pode afetar o desempenho organizacional em sentido amplo. A primeira abordagem se refere à competição por capital (SILVA; TIBURCIO; NIYAMA, 2009, p. 4-5). Este argumento, que não é novo (Botosan, 1997, 2000) para a comunidade financeira, sustenta que mais evidenciação implica menor custo de capital (acionário) porque (a) como a evidenciação aumenta a liquidez de uma ação no mercado de capitais, então os custos de transação devem cair ou deve aumentar a demanda pelos títulos das empresa que evidencia mais, ou ambas as coisas; e (b) a maior evidenciação reduz o risco do investidor ao estimar o retorno futuro ou a futura distribuição de dividendos no caso de uma empresa que evidencia mais (BOTOSAN, 1997, p. 324).

A segunda abordagem está relacionada ao custo incorrido pela organização ao ter de produzir e distribuir informações. Para Botosan (2000, p. 60), a decisão de evidenciar mais deveria estar apoiada em uma análise dos custos e benefícios. A autora lembra que, além dos custos diretos de produzir e distribuir informações, podem, ainda, ocorrer custos indiretos, tais como os decorrentes de processos legais ou do enfraquecimento da posição concorrencial. Em compensação, as ações de evidenciação podem ajudar a corrigir dificuldades ou falhas no processo de comunicação da empresa com seus públicos-alvo (id., p. 63). No caso do futebol brasileiro, alguns dos objetivos de ambas as Leis 10671/93 e 10672/93 estarão, pois, contemplados no caso de maior evidenciação pelos clubes.

Vale notar que esta segunda abordagem está relacionada à questão da quebra de assimetria informacional entre gestores e stakeholders nas sociedades sem fins lucrativos (REZENDE; FACURE; DALMÁCIO, 2009, p. 2). Uma vez que os mecanismos de governança podem oferecer proteção aos interesses dos stakeholders (id., p. 5), a eficácia do desempenho organizacional, medida tanto pelo benefício efetivo, quanto pela satisfação percebida dos stakeholders, estará então positivamente afetada.

\subsection{MENSURAÇÃO DA EVIDENCIAÇÃO DAS INFORMAÇÕES CONTÁBEIS}

A despeito de que, no Brasil, os clubes ainda não podem ser considerados corporações, neste estudo o grau de evidenciação das demonstrações de clubes de futebol tomará por base a literatura sobre evidenciação corporativa (corporate disclosure).

Em seu já clássico artigo sobre abordagens empíricas à evidenciação, Healy e Palepu (2001, p. 426-427) discutem vantagens, desvantagens e limitações associadas à construção de indicadores empíricos do grau de evidenciação (extent of disclosure). Na literatura especializada, comentam eles, os autores usaram diversos indicadores, por exemplo, opiniões gerenciais, métricas apoiadas em dados secundários, e medidas ad hoc, definidas pelo próprio pesquisador. Neste último caso, alertam para o fato de que, embora a definição pelo pesquisador geralmente aumente a confiança em que a medida efetivamente capte $o$ que se pretende, ela diminui a possibilidade de replicar os resultados, pois tais métricas dependem de julgamento do pesquisador.

Apesar de frequentemente confundidas entre si, transparência e evidenciação não coincidem. Por exemplo, a Enron evidenciava muito, mas os investidores estavam "no escuro"; na verdade, muita evidenciação pode causar ruído em vez de aumentar a transparência (HANCOCK, 2004).

Para Bushman, Piotroski e Smith (2004, p. 210), transparência (corporate transparency) é a disponibilização ampla de informações específicas sobre uma empresa (publicly listed firm) para aqueles que estão fora da organização. Os autores consideram que a intensidade de evidenciação é um dos elementos que caracterizam aquela dimensão da transparência que denominam corporate reporting (ibid., p. 211, Fig. 1) e que compreende o fornecimento periódico de informações específicas, obrigatórias por lei ou não. Para quantificar a intensidade de evidenciação Bushman, Piotroski e Smith (2004, p. 
212) utilizaram três medidas diferentes, que combinam diversos tipos de informações existentes sobre empresas industriais, geralmente de médio e grande porte; entre essas informações destacam-se os indicadores selecionados pelo CIFAR - Center for International Financial Analysis and Research.

Uma das medidas utilizadas por Bushman, Piotroski e Smith (2004) é o número médio de itens evidenciados por uma dada empresa dentre os 90 itens possíveis, recomendados em CIFAR (1995). Esta medida pode ser interpretada como a soma simples uniformemente ponderada das variáveis dummy associadas à presença (ou ausência) de cada item. Por outro lado, ao discutir seu índice de evidenciação para bancos, em que 17 tipos de informações contábeis são incluídos, Hancock (2004) questiona se algum daqueles tipos - por exemplo, informações mais frequentemente evidenciadas - deveriam receber pesos diferentes - por exemplo, diretamente proporcionais à frequência.

Estendendo a abordagem anterior, baseada em opiniões de analistas, Luo, Courtenay e Hossain (2006) constroem e aplicam um indicador direto de evidenciação voluntária (não-obrigatória), que se apóia em uma lista de 82 itens representando informações financeiras e não financeiras sobre empresas de Cingapura. Seu índice (ibid., p. 7) é essencialmente uma soma simples (não ponderada) de itens informacionais, agrupados em 3 classes - dados negociais (business data), análise gerencial sobre dados (management analysis of business data) e informações prospectivas (forward-looking information) - e pode ser escrito como

$$
\text { TDISC }_{\mathrm{i}}=\sum_{\mathrm{i}=1}^{3} \operatorname{SCORE}_{i j},
$$

onde $\mathrm{i}$ se refere à i-ésima empresa e $\mathrm{j}$, ao j-ésimo grupo de itens; $\operatorname{SCORE}_{i j}$ vale 1 se $o j$ ésimo item foi evidenciado pela i-ésima empresa, e zero em caso contrário. Antes da aplicação empírica, os autores efetuam uma padronização que faz o índice variar entre 0 (zero) e 1 (um) e por isso permite a comparação entre empresas de indústrias diferentes. Os autores efetuam verificações de consistência por meio de correlações.

Para Core (2001, p. 442), a literatura sobre evidenciação voluntária oferece grande oportunidade para aumentos significativos em nossa compreensão acerca do papel da informação contábil para avaliação de empresas e para finanças corporativas. Nesta linha a escocesa V. Beattie fornece, em dois artigos (Beattie, 2005; Beattie, Mclnnes e Fearnley, 2004), uma visão ao mesmo tempo teórica e empírica sobre a questão da evidenciação.

Do ponto de vista conceitual, Beattie (2005, p. 16) explica como o recente aumento do interesse em evidenciação pode ser associado à insatisfação com o modelo contábil tradicional, que, por enfatizar apenas informações financeiras de natureza histórica, já não atende as necessidades da grande maioria dos usuários. Além disso, a autora destaca a escola americana, que, por meio de abordagens matemáticas e hipóteses simplificadoras, tem proposto modelos para explicar a decisão de evidenciar. Em geral, esses modelos se inspiram em teoria econômica e apelam para a teoria dos incentivos e desincentivos para explicar aquela decisão.

Do ponto de vista empírico, que interessa mais a esta pesquisa, Beattie, Mclnnes e Fearnley (2004, p. 207) retomam o alerta de Healy e Palepu (2001). Destacando a longa história do caminho que consiste em que o pesquisador defina sua própria métrica e reconhecendo que, diante de tantas limitações e fraquezas, mais pesquisa é necessária para fortalecer esta área de estudos, eles propõem uma metodologia original de análise de demonstrações contábeis, que permite tanto examinar dados verbais, relativos a narrativas sobre resultados, quanto avaliar a complexa questão da mensuração da qualidade dos 
relatórios corporativos. Devido à dificuldade para analisar diretamente a questão da qualidade, Beattie, McInnes e Fearnley (2004, p. 210) discutem diversas formas de registrar a "quantidade de evidenciação" (amount of disclosure), incluindo não somente a codificação binária, pela qual a presença / ausência de um item evidenciável é assinalada com 1 (um) / 0 (zero), mas também a atribuição (subjetiva) de escores crescentes, conforme a evidenciação seja quantitativa, qualitativa ou ausente (por exemplo, 2, 1 ou 0 , respectivamente).

Também para Eng e Mak (2003), a pesquisa empírica tem longa história e em suas origens está o trabalho pioneiro de Cerf (1961). Esses autores abordam a evidenciação (voluntária) em termos da quantidade e do nível de detalhe contidos nas informações nãoobrigatórias que aparecem no relatório anual das empresas amostradas. Eles quantificam a evidenciação voluntária através de um escore agregado, construído a partir de informações não-obrigatórias, de natureza estratégica, financeira e não-financeira, para uma amostra de 158 empresas com ações negociadas na Bolsa de Cingapura. 0 escore de cada empresa é a soma dos escores que recebeu (p. 327).

0 trabalho de Chau e Gray (2002) examina e quantifica a evidenciação (voluntária) em Hong Kong e Cingapura. Apoiando-se em Meek, Roberts e Gray (1995), sua lista de itens evidenciáveis (p. 251) inclui 12 itens evidenciáveis, distribuídos nas mesmas três categorias de informações - estratégicas (5 itens), financeiras (4 itens) e não-financeiras (3 itens). De modo a quantificar o nível de evidenciação por empresa, os autores constroem um escore agregado, chamado TVD/MVD, igual ao quociente entre a soma não-ponderada do total de itens presentes e o valor máximo possível de evidenciações. Para eles, a ausência de pesos representa a hipótese - implícita e não necessariamente razoável - de que todos os itens teriam igual importância. Ademais, argumentam, esta abordagem não ponderada foi utilizada em muitos outros estudos anteriores (p. 252).

Seguindo Cooke (1989), Street e Bryant (2000) também investigaram empiricamente o nível de evidenciação por meio da construção de um escore agregado não ponderado. Sua lista incluiu, entre outros, itens que podiam ser obrigatórios segundo os U. S. GAAP, mas não eram obrigatórios segundo o IASC GAAP. Dois índices agregados não ponderados foram definidos para cada empresa (p. 315), conforme incluíssem ou não itens obrigatórios, desconsiderando os itens não aplicáveis, de modo a não penalizar empresas menores ou menos diversificadas, e evitando dupla contagem de algum item. Estes indicadores foram, depois, utilizados como variável dependente em análises estatísticas multivariadas.

Por natureza, a evidenciação é um constructo abstrato, sem características "inerentes" pelas quais se pude determinar sua intensidade ou qualidade (WALLACE e NASER, 1995). O caráter essencialmente empírico da construção de indicadores do nível de evidenciação foi claramente estabelecido por Barako, Hancock e Izan (2006), em seu estudo sobre os fatores determinantes da evidenciação voluntária no caso de empresas quenianas. Citando Marston e Shrives (1991), Barako, Hancock e Izan (2006, p. 114) afirmam que, apesar dos diversos estudos divulgados desde Cerf (1961), ainda não existe uma teoria geral para guiar a seleção de itens quando se quer medir o nível de evidenciação voluntária. Em seu estudo eles definem um indicador de evidenciação ( $p$. 114-117) que então aplicam a uma amostra de 43 empresas, escolhidas por terem ações negociadas na Bolsa Nacional do Quênia em todo o período 1992-2001 e também por terem disponibilizado seus relatórios anuais naquela Bolsa. Vale notar que, a despeito de reconhecerem a eventual subjetividade associada a qualquer esquema de pesos, Barako, Hancock e Izan (2006) decidiram adotar um esquema de ponderação para os itens que escolheram, a saber, 47 itens finais a partir de uma lista de 106 itens iniciais. Os pesos foram gerados "externamente", por meio de avaliações numéricas (em escala de 0 a 4) feitas por analistas de crédito e empréstimos de bancos quenianos. Finalmente, esses 
autores também preferiram a forma percentual, expressando seu indicador como proporção do escore máximo possível (p. 115).

\section{METODOLOGIA}

O presente estudo visa analisar as demonstrações contábeis dos clubes de futebol da $1^{\text {a }}$ divisão do campeonato brasileiro de 2004 com o objetivo de mensurar o nível de evidenciação para então relacioná-lo ao desempenho desses clubes. A evidenciação será mensurada através de um indicador que combina os seis critérios revistos nesta pesquisa, a saber, Forma e Disposição das Demonstrações Contábeis, Notas Explicativas, Quadros e Demonstrações Suplementares, Demonstrações Complementares, Parecer dos Auditores Independentes, e Relatório da Administração.

Para avaliar a relação entre evidenciação e desempenho o indicador do nível de evidenciação aqui proposto será correlacionado ao resultado financeiro, em termos dos valores obtidos na Demonstração de Resultados (DRE), e também ao desempenho efetivo em uma importante competição. A despeito de haver muitas outras formas para avaliar o desempenho organizacional, nesta pesquisa adota-se uma das possíveis medidas originadas nas demonstrações contábeis, sendo, por isso mesmo, amplamente conhecida e aceita na literatura.

A hipótese nula sobre ausência de correlação será testada não-parametricamente, por meio de coeficientes de correlação ordinal (rank correlation).

\subsection{O ÍNDICE DE EVIDENCIAÇÃO DAS DEMONSTRAÇÕES CONTÁBEIS}

A visão moderna da Contabilidade como instrumento da transparência organizacional pressupõe que os clubes estejam aptos a ser avaliados pelo mercado do qual fazem parte, e para isso deverão elaborar demonstrações de suas operações e evidenciar os resultados alcançados. A evidenciação das informações deve ser sempre aprimorada, não somente através de novas tecnologias de tratamento, mas também adicionando informações de caráter não financeiro. Cabe observar que a pouca transparência eventualmente apresentada nas demonstrações contábeis de clubes de futebol (Silva, 2009; Marques e Costa, 2007) poderia afugentar possíveis investidores e patrocinadores, além de criar possíveis problemas de imagem perante os torcedores. Sabe-se que os clubes que elaboram e divulgam demonstrações contábeis com maior nível de transparência conseguem maior exposição diante dos investidores nacionais e estrangeiros, cuja participação em alguns clubes é bastante expressiva.

Neste estudo, para efeito de análise dos níveis de evidenciação das demonstrações contábeis dos clubes foram considerados os seguintes itens: (1) a forma e disposição das demonstrações contábeis; (2) notas explicativas elucidativas; (3) quadros e demonstrações suplementares; (4) demonstrações complementares; (5) parecer dos auditores independentes; e (6) relatório da administração.

O primeiro item considerado foi a Forma e Disposição das Demonstrações Contábeis, que é seguramente o que proporciona a maior quantidade de evidenciação. Segundo ludícibus (2000, p. 119), a colocação das demonstrações contábeis em uma forma ordenada melhora sua interpretabilidade e ajuda a melhorar a evidenciação. Por outro lado, informações de muita relevância podem ser apresentadas nas demonstrações de fontes e usos de recursos e, eventualmente, em uma demonstração de caixa, nas quais os vários grupamentos deveriam ser evidenciados de maneira inteligente e global, de forma que se 
permitisse avaliar a importância relativa de cada item em seu grupo ou no total de fontes e usos.

O segundo item, as Notas Explicativas é, talvez, a mais conhecida forma de evidenciação. Seu principal objetivo é evidenciar as informações que não são apresentadas na estrutura das demonstrações contábeis. Segundo Hendriksen e Breda (1999), as principais vantagens das notas explicativas são as seguintes: (a) apresentação de informação não quantitativa como parte integral dos relatórios contábeis; (b) evidenciação das qualificações e restrições para certos itens nos demonstrativos; (c) evidenciação de maior volume de detalhes do que poderíamos apresentar nos demonstrativos; e (d) apresentação da informação quantitativa ou descritiva de importância secundária.

O terceiro elemento, os Quadros Suplementares, pode ser utilizado para apresentar maiores detalhes sobre itens que, apesar de constarem das demonstrações contábeis, não devem integrar seu corpo propriamente dito. Já as Demonstrações Suplementares, segundo ludícibus (2000, p. 120) admitem utilização mais ambiciosa, servindo para apresentar demonstrações contábeis sob uma outra perspectiva de avaliação, por exemplo, corrigidos pelo índice geral de preços, ou a custo de reposição, ou por segmentos, entre outras.

O quarto item, as Demonstrações Complementares, não é exigido na legislação pertinente, mas dão maior visibilidade à instituição, tais como, por exemplo, a demonstração do fluxo de caixa, a demonstração do valor adicionado e o balanço social.

O quinto - Parecer dos Auditores Independentes - é um importante elemento na evidenciação e tem como principal função averiguar e constatar se as demonstrações contábeis refletem adequadamente a realidade da organização que as produz. Cabe aos auditores independentes expressar uma opinião sobre as demonstrações contábeis que serão divulgadas, de acordo com as normas e princípios fundamentais de contabilidade e, para esse fim, avaliar os controles e procedimentos internos da entidade. Os serviços devem ser contratados pelo conselho de administração que deve se assegurar de que os procedimentos adotados pelos auditores garantem a independência e objetividade dos trabalhos. No processo de divulgação e de aprimoramento da informação contábil, o parecer serve, também, para conferir maior credibilidade às informações prestadas pela entidade.

O sexto e último elemento, o Relatório da Administração, é outro componente do processo de evidenciação de informações e constitui-se em peça de informação fundamental para os usuários externos. Essa forma de evidenciação, fundamentalmente de natureza descritiva, permite à entidade utilizar uma linguagem menos técnica e atingir, portanto, um maior número de usuários. 0 conceito de transparência está alicerçado nas diretrizes traçadas pelo conselho de administração, cujos membros são escolhidos pelos sócios, objetivando a redução de certos problemas internos e a busca de melhor evidenciação das operações.

Neste estudo parte-se da definição mais simples (ver § 2.3) para um indicador da evidenciação, a saber, a soma simples dos escores atribuídos pelo pesquisador aos seis elementos de evidenciação recém-discutidos, calculada para os clubes amostrados. A pontuação escolhida para definir os escores aparece no Quadro 1. Pela definição aqui adotada, os valores do indicador do nível de evidenciação podem variar entre o mínimo de 0 (zero) e o máximo de 11,5 (onze e meio) pontos.

Os dados obtidos foram tabulados e analisados através do pacote estatístico denominado SPSS ${ }^{\circledR}$ for Windows - versão 12.0. Os recursos do SPSS ${ }^{\circledR}$ permitem o cálculo direto do valor e da significância dos coeficientes calculados, aqui utilizados como teste não-paramétrico de correlação ordinal. 


\subsection{TESTE DA HIPÓTESE}

De acordo com Spiegel (1969, p. 276), testes de hipóteses são relevantes porque servem para tomar decisões acerca de populações baseadas em informações provenientes de amostras. Essas decisões denominam-se decisões estatísticas e são, normalmente, precedidas de formulação de hipóteses ou de conjeturas que constituem as hipóteses estatísticas a serem testadas. Os processos que habilitam a decidir se deve aceitar ou rejeitar uma hipótese decidir se uma hipótese deve ser aceita ou rejeitada são exatamente os testes de hipóteses ou de significância.

Quadro 1 - Pontuação utilizada para Evidenciação

\section{Forma e Apresentação das Demonstrações Contábeis}

D - Deficiente (0,5 pontos); R - Regular (1,5 pontos); B- Boa (2,5 pontos); MB - Muito Boa (4 pontos)

\section{Notas Explicativas}

D- Deficiente (0,5 pontos); PE - Pouco Elucidativas (1,0 ponto); ME - Muito Elucidativas ( 3 pontos)

\section{Quadros e Demonstrações Suplementares}

NA - Não Apresentou ( zero pontos ) ; A - Apresentou (0,5 pontos)

\section{Demonstrações Complementares}

NA - Não Apresentou ( zero pontos ); A - Apresentou (1,0 ponto)

\section{Parecer dos Auditores Independentes}

NA - N. Apres. ( 0 ); CR - Com Ressalva (1,0); PE - Parágrafo de ênfase (1,5); SR - Sem Ressalva $(2,5)$

\section{Relatório da Administração}

NA - Não Apresentou ( zero pontos )

A - Apresentou (0,5 pontos)

Seguindo a ideia de "demonstrações voltadas a objetivos" (KPMG, 2005, p. 2), a hipótese que se quer testar neste estudo diz respeito à existência de associação entre o grau de evidenciação presente em demonstrações contábeis e o desempenho empresarial. Em outras palavras, podemos estabelecer a seguinte hipótese de pesquisa:

\section{$\mathrm{H}$ : existe associação positiva entre evidenciação e desempenho esportivo, ou seja, mais evidenciação não prejudica o sucesso do clube de futebol.}

Esta hipótese de pesquisa pode ser descrita, em termos estatísticos, como a seguinte hipótese nula:

\section{$\mathrm{H}_{0}$ : não existe associação entre nível de evidenciação e desempenho esportivo.}

Devido ao tipo de dados de que se dispõe, adota-se aqui a abordagem nãoparamétrica, escolhendo-se o teste do coeficiente de correlação ordinal (rank correlation) de Spearman para testar a hipótese nula. No contexto aqui pesquisado, deu-se preferência ao teste de correlação devido à possibilidade de haver simultaneidade na relação entre as variáveis estudadas, criando então um viés que desaconselha o uso da regressão com mínimos quadrados (cf. Silva, Teixeira e Niyama, 2009). "Simultaneidade" significa que tanto a evidenciação pode influenciar o desempenho, quanto que este pode influenciar aquela, ou, ainda, que ambas as influências podem ocorrer ao mesmo tempo, e isso não deve ser ignorado na estimação da equação de regressão (BARRETO; HOWLAND, 2006, cap. 24). 
Além disso, apesar de assintoticamente virtuosa, a abordagem via regressão depende de testes paramétricos e de outros requisitos (tal como a ocorrência de erro nas variáveis) que, de certa forma, comprometem a utilização dos coeficientes de regressão para testar hipóteses no presente contexto empírico.

Em contraste, a literatura aponta vários benefícios decorrentes de testar uma hipótese nula através de um teste não-paramétrico

Por exemplo, para Siegel (1975, p. 34) dentre as principais vantagens dessa classe de testes pode-se indicar que:

* não é necessário especificar condições sobre os verdadeiros parâmetros da população da qual se extrai a amostra;

- não se exigem mensurações tão restritas quanto o que ocorre no caso paramétrico; e

- as suposições básicas feitas no caso não-paramétrico são em menor número e mais fracas do que no caso paramétrico.

Nas palavras de Freund e Simon (2000, p. 351), o teste de correlação ordinal é um teste da hipótese de que não há correlação, que é exatamente a forma da hipótese nula acima. A presente pesquisa utiliza o teste não-paramétrico do coeficiente de correlação ordinal Rô $(\rho)$ de Spearman, que está entre as medidas ordinais mais usadas e que consiste em correlacionar a ordem de classificação entre duas variáveis ordenadas. Segundo Cooper e Schindler (2003, p 445), a utilização do Rô de Spearman apresenta algumas vantagens, a saber: (1) quando os dados são transformados por logaritmos ou por elevação ao quadrado, o Rô não se altera; (2) pontos ou escores extremos que representavam problemas antes da classificação não representam mais ameaças, pois o maior número na distribuição é igual ao tamanho da amostra e (3) é uma estatística de fácil compreensão e de cálculo simples.

\subsection{AMOSTRA E COLETA DOS DADOS}

As demonstrações contábeis - Balanço Patrimonial e Demonstração do Resultado do Exercício - referentes aos exercícios de 2004 e 2003 dos 17 clubes que compõem a amostra estavam disponíveis em diversos jornais de todo o País, devido à prescrição legal de publicação.

No presente estudo são analisadas as demonstrações contábeis do exercício de 2004, relativas a participantes do campeonato brasileiro de 2004. Como foi explicado antes, não foi possível ter acesso às demonstrações de 5 dos 22 clubes que disputaram esse campeonato - a saber, Brasiliense, Fortaleza, Goiás, Juventude e Payssandu. Estes clubes foram, então, eliminados do estudo. A amostra de conveniência aqui utilizada contou, portanto, com a presença de 17 clubes, sendo 4 do Rio de Janeiro, 6 de São Paulo, 2 de Minas Gerais, 3 do Paraná, 1 do Rio Grande do Sul, 1 de Santa Catarina. Se se restringir o conceito de eficácia da organização esportiva ao desempenho no campeonato brasileiro que é, em muitos sentidos, a mais importante competição nacional do futebol brasileiro pode-se considerar essa amostra como representando pouco mais de $77 \%$ da população relevante.

Como será possível constatar ao longo do trabalho, nem o tamanho da amostra, nem o período escolhido representam qualquer dificuldade para estender a metodologia empregada tão logo haja mais e melhores dados. 


\section{RESULTADOS}

Os resultados do cálculo dos indicadores de evidenciação para cada clube da amostra aparecem na Tabela 1. Os escores ("pontos") calculados variaram entre 3,0 (três, para o Vasco da Gama) e 10,5 (dez e meio, para o Palmeiras).

Tabela 1 - Ranking dos Clubes da Amostra

\begin{tabular}{|c|c|c|c|c|}
\hline Classificação no Campo & \multicolumn{2}{|c|}{ Resultado Financeiro } & \multicolumn{2}{|c|}{ Nível de Evidenciação } \\
\hline RANKING & RANKING & Milhões de R\$ & RANKING & Pontos \\
\hline $1^{\circ}$ SANTOS & $1^{\circ}$ INTERNACIONAL & 15,5 & $1^{\circ}$ PALMEIRAS & 10,5 \\
\hline $2^{\circ}$ ATLÉTICO PR & $2^{\circ}$ CORINTHIANS & 13,6 & $2^{\circ}$ CORINTHIANS & 10,0 \\
\hline $3^{\circ} \mathrm{SÃO}$ PAULO & $3^{\circ}$ SANTOS & 10,2 & $3^{\circ}$ ATLÉTICO PR & 10,0 \\
\hline $4^{\circ}$ PALMEIRAS & $4^{\circ}$ PALMEIRAS & 8,8 & $4^{\circ} \mathrm{SÃO}$ PAULO & 9,5 \\
\hline $5^{\circ}$ CORINTHIANS & $5^{\circ} \mathrm{SÃO}$ CAETANO & 5,3 & $5^{\circ}$ SANTOS & 9,5 \\
\hline $8^{\circ}$ INTERNACIONAL & $6^{\circ}$ FLAMENGO & 0,2 & $6^{\circ}$ PARANÁ & 9,0 \\
\hline $9^{\circ}$ FLUMINENSE & $7^{\circ} \mathrm{CRUZEIRO}$ & 0,1 & $7^{\circ}$ FIGUEIRENSE & 8,5 \\
\hline $10^{\circ}$ PONTE PRETA & $8^{\circ}$ FIGUEIRENSE & 0,1 & $8^{\circ} \mathrm{SÃO}$ CAETANO & 8,0 \\
\hline $11^{\circ}$ FIGUEIRENSE & $9^{\circ}$ ATLÉTICO PR & $-0,1$ & $9^{\circ}$ CORITIBA & 7,5 \\
\hline $12^{\circ}$ CORITIBA & $10^{\circ}$ CORITIBA & $-0,7$ & $10^{\circ} \mathrm{CRUZEIRO}$ & 7,0 \\
\hline $13^{\circ} \mathrm{CRUZEIRO}$ & $11^{\circ}$ PARANÁ & $-1,1$ & $11^{\circ}$ INTERNACIONAL & 6,5 \\
\hline $15^{\circ}$ PARANÁ & $12^{\circ}$ PONTE PRETA & $-1,7$ & $12^{\circ}$ FLUMINENSE & 5,5 \\
\hline $16^{\circ}$ VASCO DA GAMA & $13^{\circ} \mathrm{SÃO}$ PAULO & $-2,0$ & $13^{\circ}$ FLAMENGO & 5,0 \\
\hline $17^{\circ}$ FLAMENGO & $14^{\circ}$ FLUMINENSE & $-5,5$ & $14^{\circ}$ ATLÉTICO MG & 4,5 \\
\hline $18^{\circ} \mathrm{SÃO}$ CAETANO** & $15^{\circ} \mathrm{BOTAFOGO}$ & $-8,3$ & $15^{\circ}$ BOTAFOGO & 4,0 \\
\hline $19^{\circ}$ ATLÉTICO MG & $16^{\circ}$ ATLÉTICO MG & $-26,4$ & $16^{\circ}$ PONTE PRETA & 3,5 \\
\hline $20^{\circ}$ BOTAFOGO & $17^{\circ}$ VASCO DA GAMA & $-46,9$ & $17^{\circ}$ VASCO DA GAMA & 3,0 \\
\hline
\end{tabular}

Antes de realizar o teste da hipótese, considerou-se que o resultado obtido para o Vasco da Gama sugeria uma análise mais cuidadosa da situação do clube carioca em termos da amostra como um conjunto. Procedeu-se, então, a duas verificações da eventual excepcionalidade do clube dentro do grupo. Primeiro, calculou-se o box plot (Hair et al., 1998, p. 42-43) para as seis variáveis que comporiam o indicador, e, de fato, o Vasco mostrou-se um outlier (Hair et al., ibid., p. 64-70) para a maioria delas, confirmando que as análises deveriam desconsiderar esse clube. Segundo, após uma análise de cluster (Hair et al., ibid., capítulo 9) baseada naquelas seis variáveis, o clube ficou isolado em um único cluster até o final da aglomeração dos clusters. Mais adiante outros procedimentos 
confirmarão a decisão de retirar o Vasco das análises.

Outro ponto que vale destacar é a questão da consistência do indicador "nível de evidenciação". Em geral, conforme afirmam Hair et al. (ibid., p. 118), nenhum elemento isoladamente é capaz de medir um constructo. Assim, ao considerar as seis variáveis selecionadas como elementos de um mesmo constructo - a saber, o nível de evidenciação é desejável avaliar a consistência interna entre esses componentes (ou "itens").

Uma das medidas mais usadas para avaliar consistência é o chamado "coeficiente de confiabilidade alfa de Cronbach", que deve ser igual ou superior a 0,70 (0,60 em pesquisas exploratórias) (HAIR et al., ibid., p. 118). Calculando esse coeficiente com dados relativos àquelas seis variáveis, chega-se, inicialmente, ao valor de 0,515 , indicando que se deve fazer uma depuração no conjunto de elementos. A depuração procede por eliminação, retirando-se sucessivamente cada variável cuja ausência permita aumentar a confiabilidade. Feito isto, chega-se a um conjunto final contendo 4 variáveis - Forma e Disposição; Quadros Suplementares; Demonstrações Complementares; e Relatório da Administração - às quais corresponde um coeficiente alfa igual a 0,64, aceitável para a presente pesquisa.

Uma providência que pode ajudar a verificar a robustez dos resultados da pesquisa é trabalhar com dados percentuais, que são menos afetados pela forma como são atribuídos os "pontos" às várias formas de evidenciação. Com efeito, quando os escores são redefinidos como percentagens dos totais possíveis em cada variável, tanto a atipicidade do Vasco se confirma, quanto melhora o valor do coeficiente alfa, que passa a igualar 0,712 . Além disso, as mesmas quatro variáveis permanecem, agora em forma percentual. Diante disso resolveu-se efetuar uma Análise de Componentes Principais (Hair et al., ibid., p. 102-103; Manly, 2005, cap. 6) para verificar a robustez desse grupo de quatro variáveis. De fato, esta análise confirmou que as quatro variáveis pertencem a um mesmo componente, conforme ilustram os números em negrito na segunda coluna ("Componente 1") da matriz que aparece na Tabela 2. Na primeira coluna as variáveis estão designadas pelas abreviaturas mnemônicas dos elementos de evidenciação discutidos antes.

Tabela 2 - Componentes Principais - Variáveis em Percentual

\begin{tabular}{|c|c|c|c|c|c|c|}
\hline VARIÁVEIS & \multicolumn{7}{|c|}{ Componentes } \\
\hline & 1 & 2 & 3 & 4 & 5 & 6 \\
\hline Forma_PCT & $\mathbf{0 , 8 6 8}$ & 0,215 & 0,104 & $-0,072$ & $-0,074$ & $-0,424$ \\
\hline Notas_PCT & $\mathbf{0 , 6 9 5}$ & 0,382 & 0,261 & $-0,448$ & $-0,111$ & 0,300 \\
\hline Suple_PCT & 0,419 & $-0,497$ & 0,627 & 0,417 & $-0,062$ & 0,080 \\
\hline Comple_PCT & $\mathbf{0 , 6 6 2}$ & $-0,237$ & $-0,262$ & 0,015 & 0,657 & 0,073 \\
\hline Parece_PCT & $-0,163$ & 0,813 & 0,205 & 0,450 & 0,259 & 0,029 \\
\hline Relato_PCT & $\mathbf{0 , 6 1 6}$ & 0,074 & $-0,531$ & 0,425 & $-0,366$ & 0,133 \\
\hline
\end{tabular}

\subsection{EVIDENCIAÇÃO CONTÁBIL E DESEMPENHO DOS CLUBES DE FUTEBOL}

Analisando os resultados financeiros, a classificação no campo e a evidenciação das demonstrações contábeis, segundo o nível de transparência mensurado conforme o indicador aqui proposto, pode-se constatar que os clubes que oferecem melhor nível de evidenciação em suas demonstrações são também os clubes que conseguem melhores resultados no campo e também melhores resultados financeiros. Essas variáveis devem caminhar juntas para que o sucesso do clube não seja somente momentâneo, e também para que seu desempenho possa ser considerado eficiente e eficaz. 
Observa-se, na Tabela 1, que, entre os 5 primeiros colocados em ordem de evidenciação, 4 são do Estado de São Paulo; e que esses mesmos clubes são os que ficaram entre os 5 primeiros na classificação no campo. Além disso, 3 desses clubes aparecem entre os 5 melhores resultados financeiros. Na parte oposta da tabela, verifica-se que dos 5 últimos clubes no ranking da evidenciação, 4 deles apresentaram péssimo resultado no campo e 3 estão entre os piores resultados financeiros.

Para testar a hipótese através de uma abordagem mais quantitativa, foram calculados os coeficientes de correlação ordinal de Spearman entre o nível de evidenciação e o desempenho em campo, ou seja, a classificação final no campeonato brasileiro de 2004, para as duas formas de cálculo do escore - com e sem eliminação de consistência. Os resultados obtidos foram, respectivamente, -0,624 e -0,631, ambas as correlações sendo significantes a $1 \%$. Considerando que a ordem de classificação no campeonato é crescente, ou seja, varia de 1 (o campeão) ao último dentre os clubes amostrados, este resultado mostra que mais evidenciação está associada a melhor desempenho no campo. Neste sentido pode-se entender que evidenciação e desempenho estão positiva e significativamente associados.

Segundo a literatura (Siegel, 1975, p. 237), quando ocorrem observações empatadas em alguma das variáveis - caso de São Paulo e Santos na última coluna da Tabela 1 - o coeficiente de Spearman tende a superestimar a correlação. Para lidar com empates indica-se o uso do coeficiente de correlação ordinal de Kendall, que tem até outras vantagens (SIEGEL, 1975, p. 270). Utilizando a versão de Kendall, a correlação ordinal entre o nível de evidenciação e o desempenho em campo (classificação final no campeonato brasileiro de 2004) alcançou o valor de -0,486 para o cálculo do escore com eliminação de consistência (significativo a $1 \%$ ) e de $-0,463$ no caso sem eliminação (significativo a 5\%). Apesar da (esperada) diminuição, os valores obtidos e suas significâncias ainda permitem sustentar que evidenciação e desempenho estão positiva e significativamente associados.

O cálculo das correlações entre nível de evidenciação e desempenho financeiro, medido na terceira coluna da Tabela 1, produziu essencialmente os mesmo resultados significativos, mas não serão expostos aqui. 


\section{CONCLUSÕES}

É inegável que os grandes clubes de futebol são objeto da paixão de milhares de torcedores. Entretanto, a despeito de todos os aspectos positivos do futebol, não existe garantia de que o futebol como negócio seja lucrativo como era de esperar. No Brasil, "país do futebol", muitas instituições centenárias possuem marca muito forte, mas não conseguem ter ou manter condições financeiras de honrar seus compromissos. Em outras palavras, parece premente a revisão do atual modelo de negócio do futebol brasileiro (LEONCINI, 2001). Rever modelos de negócio requer, ao mesmo tempo, rever mecanismos de governança. O presente trabalho foi desenvolvido com o objetivo de ilustrar que a evidenciação, reconhecidamente uma dimensão importante da governança, está de tal forma associada ao desempenho dos clubes amostrados que a busca de evidenciação não acarreta que a organização desportiva perca eficiência ou eficácia.

Para alcançar este objetivo o trabalho se desenvolveu em três movimentos. Primeiramente a pesquisa definiu e calculou uma medida empírica para a evidenciação das demonstrações contábeis apresentadas por uma amostra de clubes de futebol. A seguir, buscou avaliar o desempenho desses clubes sob duas óticas: (a) escolhendo uma medida de desempenho proveniente de seus demonstrativos contábeis, em consonância com as exigências contidas na Lei 6.404/76, e (b) através do desempenho efetivo dos clubes em um importante campeonato de que participaram. Outros objetivos organizacionais - tais como melhoria da imagem, valorização da marca e dos atletas, ou satisfação dos torcedores - não foram tratados aqui, assim como também não se buscou informação sobre o desempenho dos clubes amostrados em diferentes anos e campeonatos. Finalmente, foi mostrado que os clubes que evidenciam suas demonstrações contábeis em maior grau são essencialmente os mesmos que apresentam melhores resultados no campo e em termos de resultado financeiro (receitas menos despesas).

É sempre mais proveitoso trabalhar com transparência e honestidade. Todos saem ganhando. Neste estudo foi possível mostrar que esta idéia não é apenas um ideal romântico, mas uma possibilidade empiricamente confirmada, segundo a evidência empírica fornecida pelo campeonato brasileiro de futebol de 2004.

Se o futebol brasileiro possui os melhores jogadores, se está sempre revelando novos craques, se possui um estilo próprio e consagrado de jogar, se os clubes e a seleção possuem uma tradição riquíssima, se as torcidas são apaixonadas, então o país tem tudo para conseguir maior retorno financeiro para seu patrimônio. Campeonatos bem organizados, com clubes bem administrados, com uma fórmula de disputa justa, poderiam ser uma atração indiscutível e economicamente lucrativa.

No Brasil, os clubes sempre foram considerados entidades sem fins lucrativos e, antes da Lei Pelé, nunca prestaram contas à sociedade. As irregularidades na gestão desses clubes e a atual legislação esportiva obrigam os gestores a repensar suas políticas de resultados, fazendo com que a sobrevivência financeira passe a ser a principal preocupação destas instituições daqui por diante.

No mundo, o futebol é considerado um grande negócio, que apresenta crescimento contínuo e movimenta recursos vultosos, divulgados diariamente nos meios de comunicação. Observa-se, ao longo do tempo, diversas transformações no ambiente das organizações esportivas que têm influenciado suas formas de gestão. A modernização que se espera para o futuro dessas organizações que comandam o futebol profissional deve influenciar os vários níveis organizacionais dessa indústria de lazer, e principalmente, um melhor entendimento dos seus verdadeiros papéis sociais e econômicos.

Das limitações metodológicas remanescentes decorrem algumas indicações de 
pesquisa futura. No que se refere aos dados, considerando que a obrigatoriedade de evidenciação não se limita aos clubes de primeira divisão, pode-se estender o exercício empírico a uma amostra contendo clubes de outras divisões, além de procurar aumentar a cobertura temporal dos dados. Quanto ao indicador de desempenho, cabe reconhecer que apenas uma forma simples de abordá-lo foi tentada aqui, sendo recomendável repetir os testes para outras medidas igualmente reconhecidas e aceitas. Quanto ao indicador de evidenciação, a despeito de sua presença na literatura internacional resenhada, deve-se tentar avaliar, através de simulações adequadas, a sensibilidade dos resultados à utilização de ponderações e de valores diferentes dos que compõem a fórmula simples aqui adotada. 0 mesmo pode ser dito quanto à forma de expressar os valores, se em termos absolutos ou relativos. Vale lembrar que a presente utilização de um teste não paramétrico deve ter conferido alguma estabilidade aos resultados obtidos. Finalmente, a questão da consistência interna dos itens a incluir na fórmula, ausente na literatura internacional, merece mais e melhor análise. 


\section{REFERÊNCIAS}

AMADOR, R. P. Avaliação de empresas: Uma aplicação aos clubes de futebol. 134f. 2004. Dissertação (Mestrado em Ciências Contábeis). Programa Multidisciplinar e Inter-regional de Pós-Graduação em Ciências Contábeis. Brasília, 2004.

BARAKO, D. G.; HANCOCK, P.; IZAN, H. Y. Factors influencing voluntary corporate disclosure by Kenian companies. Corporate Governance, v. 14, n. 2, p. 107-125.

BARRETO, H.; HOWLAND, F. M. Introductory Econometrics: using Monte Carlo simulation with Microsoft Excel. New York: Cambridge University Press, 2006.

BEATTIE, V.; MCINNES, B.; FEARNLEY, S. A methodology for analysing and evaluating narratives in annual reports: a comprehensive descriptive profile and metrics for disclosure quality attributes. Accounting Forum. v. 28, n. 3, p. 205-236.

BEATTIE, V. Moving the financial accounting research front forward. The British Accounting Review, v. 37, n. 1, p. 85-114.

BOTOSAN, C. A. Disclosure level and the cost of equity capital. The Accounting Review, v. 72, n. 3, p. 323-349, 1997.

- Evidence that greater disclosure lowers the cost of equity capital. Journal of Applied Corporate Finance, v. 12, n. 4, p. 60-69, 1997.

BUSHMAN, R. M.; PIOTROSKI, J. D.; SMITH, A. J. What determines corporate transparency ? Journal of Accounting Research, v. 42, n. 2, p. 207-252.

CERF, A. R Corporate Reporting and Investment Decisions, Berkeley, CA: University of California Press.

CHAU, G. K.; GRAY, S. J Ownership structure and corporate voluntary disclosure in Hong Kong and Sinagapore The International Journal of Accounting, v. 37, n. 2, p. 247-265.

CIFAR - Center for International Financial Analysis and Research. International Accounting and Auditing Trends, 4 ed. Princeton, N. J.: CIFAR Publ.

COOKE, T. Disclosure in the corporate annual reports of Swedish companies Accounting and Business Research, v. 19, n. 74, p. 113-124.

COOPER, D. R.; SCHINDLER, P. S. Métodos de Pesquisa em Administração, 7 ed. Porto Alegre: Bookman.

CORE, J. E. A review of the empirical disclosure literature: discussion. Journal of Accounting and Economics, v. 31, n. 3, p. 441-456.

ENG, L. L.; MAK, Y. T. Corporate governance and voluntary disclosure. Journal of Accounting and Public Policy, v. 22, n. 4, p. 325-345.

FERreirA, A. B. de H. Novo Dicionário Aurélio da Língua Portuguesa, 3 ed. Curitiba: Positivo Livros.

FREUND, J. E.; SIMON, G. A. Estatística aplicada: Economia, Administração e Contabilidade. 9. ed. Porto Alegre: Bookman.

GRAY, S. J.; RADEBAUGH, L. H.; ROBERTS, C. B. International perceptions of cost constraints on voluntary information disclosures: a comparative study of U.K. and U.S. multinationals. Journal of International Business Studies, v. 21, n. 4, p. 597-622, 1990.

HAIR, J. F.; ANDERSON, R. E.; TATHAM, R. L.; BLACK, W. C. Multivariate Data Analysis. 5 ed. Upper Saddle River, N. J.: Prentice Hall. 
HANCOCK, D. Discussion: disclosure, volatility and transparency. Workshop on Accounting, Transparency and Bank Stability, Bank for International Settlements, Basiléia, 17 e 18 de maio.

HEALY, P. M.; PALEPU, K. G. Information asymmetry, corporate disclosure, and the capital markets: a review of the empirical disclosure literature. Journal of Accounting and Economics, v. 31, n. 3, p. 405-440.

HENDRIKSEN, E. S.; BREDA, M. F. Van.Teoria da Contabilidade. Tradução de Antonio Zoratto Sanvicente. São Paulo: Atlas, 1999.

IUDÍCIBUS, S. de. Teoria da Contabilidade. 6. ed. São Paulo: Atlas, 2000.

KPMG. SEC staff proposals on accounting for off-balance sheet-arrangements. Defining Issues, n. 05-11, Jun. p. 2.

LEONCINI, M. P., Entendendo o Negócio Futebol: Um estudo sobre a transformação do modelo de gestão estratégica nos clubes de futebol. 168f. 2001. Tese (Doutorado em Engenharia de Produção). Faculdade de Economia, Administração e Contabilidade da Universidade de São Paulo. São Paulo, 2001.

LUO, S.; COURTENAY, S. M.; HOSSAIN, M. The effect of voluntary disclosure, ownership structure and proprietary cost on the return-future earnings relation. Pacific Basin Finance Journal, v. 14, n. 5, p. 501-521.

MANLY, B. F. F. Multivariate Statistical Methods: a primer. 3.ed. Chapman \& Hall - CRC, 2005.

MARQUES, D. S. P.; COSTA, A. L. Estudo comparativo sobre governança corporativa: análise de três clubes de futebol do estado de São Paulo. In Encontro Nacional da ANPAD, XXXI, 2007, Rio de Janeiro. Anais do XXXI Encontro da ANAPAD. Rio de Janeiro: ANPAD, 2007.

MARSTON, C. L.; SHRIVES, P. J. The use of disclosure indices in accounting research: a review article. The British Accounting Review, v. 23, n. 3, 1991, p. 195-210.

MEEK, G. K.; ROBERTS, C. B.; GRAY, S. J. Factors influencing voluntary annual report disclosures by US, UK and continental European multinational corporations. Journal of International Business Studies, v. 26, n. 3, 1995, p. 555-572.

NETO, F. P. M. Administração e Marketing de Clubes Esportivos. Rio de Janeiro: Sprint, 1998.

REZENDE, A. J.; FACURE, C. E. F.; DALMÁCIO, F. Z. Práticas de governança corporativa em organizações sem fins lucrativos. In Congresso USP de Controladoria e Contabilidade, 9, 2009, São Paulo. Anais do $9^{\circ}$ Congresso USP de Controladoria e Contabilidade. São Paulo: FEA - USP, 2009.

SIEGEL, S. Estatística não-paramétrica para as ciências do comportamento. São Paulo: McGraw-Hill do Brasil, 1975.

SILVA, J. A. F. A transparência das demonstrações financeiras em organizações desportivas: um estudo da evidenciação contábil em clubes de futebol. In Congresso USP de Controladoria e Contabilidade, 7, 2007, São Paulo. Anais do $7^{\circ}$ Congresso USP de Controladoria e Contabilidade. São Paulo: FEA - USP, 2007.

SILVA, C. A. T.; TEIXEIRA, H. M.; NIYAMA, J. K. Evidenciação contábil em entidades desportivas: uma análise dos clubes de futebol brasileiros. In Congresso USP de Controladoria e Contabilidade, 9, 2009, São Paulo. Anais do $9^{\circ}$ Congresso USP de Controladoria e Contabilidade. São Paulo: FEA - USP, 2009.

SKOGSVIK, K. Conservative accounting principles, equity valuation and the importance of voluntary disclosures. British Accounitng Review, v. 30, p. 361-381, 1998. 
SPIEGEL, M. R. Estatística. 2 ed. Rio de Janeiro: Livro Técnico, 1969.

STREET, D. L.; BRYANT, S. M. Disclosure level and compliance with IASs: a comparison of companies with and without $U$. S. listings and filings. The International Journal of Accounting, v. 35, n. 3, 2000, p. 305-329.

WALLACE, R. S. O.; NASER, K. Firm-specific determinants of comprehensiveness of mandatory disclosure in the corporate annual reports of firms in the Stock Exchange of Hong Kong. Journal of Accounting and Public Policy, v. 14, n. 4, 1995, p. 311-368.

WILLIAMSON, O. E. The economic institutions of capitalism. New York: Freeman, 1985.

ZIMBWA, C. An empirical assessment of transparency in Zambia. Working Paper, Centre for Corporate Governance and Regulation, Bournemouth University, 2005.

\section{ENDEREÇO DOS AUTORES}

Banco Nacional do Desenvolvimento Econômico e Social

Avenida República do Chile, 100 - Centro

Rio de Janeiro, RJ - Brasil

20031-917

Faculdade de Administração e Finanças Universidade do Estado do Rio de Janeiro Rua São Francisco Xavier, 524, $9^{\circ}$ andar, bloco E - Maracanã Rio de Janeiro, RJ - Brasil - Caixa Postal 68514

20550-013 